\title{
VALIDITY OF SELECTED CARDIOVASCULAR FIELD-BASED TEST AMONG MALAYSIAN HEALTHY FEMALE ADULT
}

\author{
S. H. Azmi ${ }^{1, *}$, and N. Sulaiman ${ }^{2}$ \\ ${ }^{1}$ Faculty of Sport Science and Coaching, Universiti Pendidikan Sultan Idris, Perak, Malaysia \\ ${ }^{2}$ Faculty of Sport Science and Recreation, Universiti Teknologi MARA, Shah Alam, Malaysia
}

Published online: 10 November 2017

\begin{abstract}
Based on emerge obese problem among Malaysian, this research is formulated to validate published tests among healthy female adult. Selected test namely; 20 meter multi-stage shuttle run, $2.4 \mathrm{~km}$ run test, 1 mile walk test and Harvard Step test were correlated with laboratory test (Bruce protocol) to find the criterion validity among test in predicting $\mathrm{VO}_{2} \max$ for the Malaysian healthy female adults. Based on the data analysis, 20 meter multi-stage shuttle run test showed higher correlation $(\mathrm{r}=.634, \mathrm{p}=0.01, \mathrm{p}<0.05)$, compare to the other test which are $2.4 \mathrm{~km}$ run test $(\mathrm{r}=.414, \mathrm{p}=.125, \mathrm{p}>0.05)$, One mile walk test $(\mathrm{r}=.182, \mathrm{p}=.517, \mathrm{p}>0.05)$ and Harvard Step test $(r=.309, p=.267, p>0.05)$. Based on this research its proven that the most suitable cardiovascular test to measure $\mathrm{Vo}_{2} \max$ among healthy female adult is 20 meter multi-stage shuttle run test.
\end{abstract}

Keywords: Criterion validity, field based test, laboratory test, healthy female adult

Author Correspondence, e-mail: siti.hartini@fsskj.upsi.edu.my

doi: http://dx.doi.org/10.4314/jfas.v9i6s.91 


\section{INTRODUCTION}

Health-Related physical Fitness has incorporated the five major components of fitness to improve health. The components are such as flexibility, muscular endurance, body composition, cardiovascular endurance and muscular strength. In order to become physically fit and promote positive attitudes toward fitness it is critical to understand, learn and apply the concepts and principles of health-related fitness [1].

Cardiovascular fitness is one of the health related physical fitness component which represent the efficiency of our heart, lungs and vascular system delivering oxygen to working muscle so that can be sustained for long lasting activity. The indicator of cardiovascular fitness are include resting heart rate, resting blood pressure, cardiac output, stroke volume, maximal oxygen consumption, and endurance capacity. So, fit individual is expected to have a lower blood pressure, increase cardiac output, decreased resting heart rate, increased SV, increase in $\mathrm{VO}_{2} \mathrm{max}$, and increased work endurance capacity.

Fitness test can be divided into two, which is field test and lab test. Lab test is always state as more valid compare to field test, but only small number of subjects can be tested in one session due to long period of time will be taken to complete the test. Field test more suitable to test big group of subjects in one time. Example of lab test for cardiovascular fitness test is Astrand Cycle Test and Bruce Protocol test. Examples of field test for cardiovascular fitness test are $2.4 \mathrm{~km}$, Bleep Test and 6 minutes walk test. During fitness test for big sample, most researchers use the field based test because able to test many subjects in one time, easy and less costing.

The maximal oxygen consumption $\left(\mathrm{VO}_{2} \mathrm{max}\right)$ that obtained during the graded maximal exercise is considered as an objective to measure the cardiorespiratory fitness. Maximal oxygen consumption actually referring to the single highest oxygen uptake that elicited during graded exercise to exhaustion. Maximal oxygen consumption is depending on the amount of muscle mass that involved during the test. In this studied, the Bruce Treadmill laboratory test had been chosen as the criterion test. The result of the selected cardiovascular field based result will be compare with the criterion test. The Bruce treadmill test is the most commonly used incremental graded exercise test used to measure $\mathrm{VO}_{2} \max$ and to evaluate cardiovascular function. 


\section{METHOD}

This study is to investigate the correlation between selected field based test, using 20 meter multi-stage shuttle run [2], 2.4km run test [3], 1 mile walk test [4] and Harvard Step test [5] and laboratory test using Bruce protocol in predicting $\mathrm{VO}_{2} \max [6]$ for the Malaysian healthy female adults.

\subsection{Research Design}

This research used correlational research designs to examine the relationship between selected cardiovascular field based test and the maximal oxygen consumption using Bruce Protocol Test among healthy female adults (fig. 1)

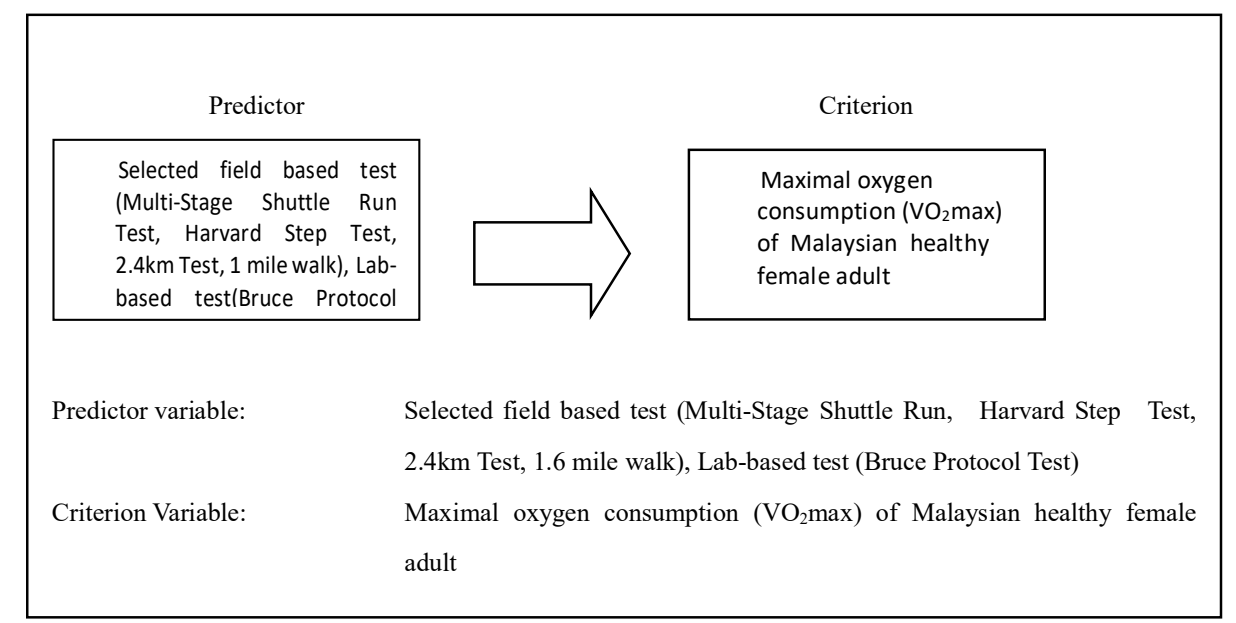

Fig.1. Predictor variable and criterion variable.

\subsection{Sample selection}

15 healthy female adult aged 20 to 24 years old were randomly selected to participate in this research. All the participants have to complete the Physical Activity Readiness Questionnaire (PAR-Q) before they being selected as a subject for these study.

\subsection{Data collection procedure}

This study is using a maximum effort tests to measure cardiovascular endurance among selected subject. Thus subject given 7 days of resting time in between the test. Data collection 
started when researcher obtain an ethical approval from Ethical Committee from university. Week one, subject performing Multi-Stage Shuttle Run Test, following by Harvard Step Test in week two. In week three they perform $2.4 \mathrm{~km}$ run test and then continue by 1 miles walk on week 4. Then, on week five, subject will undergo lab based test, which is Bruce Protocol Test.

\section{RESULTS AND DISCUSSION}

\subsection{Descriptive Data}

Descriptive data for age, height, weight and body mass index (BMI) were collected and analyzed for each subjects. Minimum and maximum value, median, mean and standard deviation are presented in Table 1 below.

Table 1. Descriptive data of subject

\begin{tabular}{lllll}
\hline & Min & Max & Mean & SD \\
\hline Age(Years old) & 20 & 24 & 21.7 & 1.0 \\
Weight $(\mathrm{kg})$ & 40 & 59 & 51.1 & 5.6 \\
Height $(\mathrm{cm})$ & 150 & 163 & 156.9 & 3.9 \\
BMI $(\mathrm{Kg} / \mathrm{m} 2)$ & 17.7 & 25.2 & 20.9 & 2.3 \\
\hline
\end{tabular}

Table 1 show the summary of descriptive data. All subjects for this study were in their twenties $(\mathrm{n}=15)$. Statistical analysis shown the mean \pm standard deviation for age were $21.7 \pm 1.0$ years. The mean \pm standard deviation for weight were $51.1 \pm 5.6 \mathrm{~kg}$. The minimum weight of subject was $40 \mathrm{~kg}$ and maximum weight of subject was $59 \mathrm{~kg}$. The mean \pm standard deviation for height were $156.9 \pm 3.9 \mathrm{~cm}$. The minimum height of subject was $150 \mathrm{~cm}$ and maximum height of subject was $163 \mathrm{~cm}$. The mean \pm standard deviation for BMI of subject was $20.9 \pm 2.3 \mathrm{~kg} / \mathrm{m}^{2}$. The minimum BMI of subject was $17.7 \mathrm{~kg} / \mathrm{m}^{2}$ and the maximum BMI of subject was 25.2 $\mathrm{kg} / \mathrm{m}^{2}$. 


\subsection{Hypothesis testing}

Table 2. Correlation between selected test and criterion test.

\begin{tabular}{|c|c|c|c|}
\hline & & Bruce & \\
\hline \multirow{8}{*}{ Pearson } & \multirow{2}{*}{$\begin{array}{l}\text { Multi-Stage Shuttle } \\
\text { Run Test }\end{array}$} & Correlation coefficient & $.634 *$ \\
\hline & & Sig. (2 tailed) & $.001 *$ \\
\hline & \multirow[t]{2}{*}{$2.4 \mathrm{~km}$ run test } & Correlation coefficient & .41 \\
\hline & & Sig. (2 tailed) & .13 \\
\hline & \multirow[t]{2}{*}{1 mile walk test } & Correlation coefficient & .18 \\
\hline & & Sig. (2 tailed) & .52 \\
\hline & \multirow[t]{2}{*}{ Harvard step test } & Correlation coefficient & .31 \\
\hline & & Sig. (2 tailed) & .27 \\
\hline
\end{tabular}

*. Correlation is significant at the 0.05 level (2-tailed).

Based on the analysis as stated as in table above, it can be conclude Multi-Stage Shuttle Run Test, $2.4 \mathrm{~km}$ run, 1 mile walk test and Harvard step test show the significant correlation with criterion test. Among the four selected field-based test, the Bleep test showed the highest correlation $(\mathrm{r}=.634, \mathrm{p}=0.01, \mathrm{p}<0.05)$, compare to the other test which are $2.4 \mathrm{~km}$ run test $(\mathrm{r}=.414, \mathrm{p}=.125, \mathrm{p}>0.05)$, One mile walk test $(\mathrm{r}=.182, \mathrm{p}=.517, \mathrm{p}>0.05)$ and Harvard Step test $(\mathrm{r}=.309, \mathrm{p}=.267, \mathrm{p}>0.05)$.

\section{DISCUSSION AND CONCLUSION}

In present 20 meter multi-stage shuttle run showed there is significant correlation with the criterion test $(\mathrm{r}=.63, \mathrm{p}=0.01, \mathrm{p}<0.05)$. Study by Barnett, Chan [7] showed the correlation between criterion test and 20 meter shuttle run is higher compared to the present study, which is 0.72. The subject for this studied were fifty-one, compared to present study that only involve fifth-teen subjects. In this study, researcher had used different surface for female and male, which was concrete surface for male and wooden surface for female. Present study used the 100 meter track for the test. The past study by [8]. The criterion test used by both study were the 
same, which is treadmill laboratory test. This study involved only thirty-three subject compare to past study that involves fifty-one subjects. Then study by Guerra, Pitetti [9] is moderate, which is only 0.56 . This is because the test has been done for special population, which is Down syndrome population. Researcher was tried to proved whether the 20 meter shuttle run test is valid for Down Syndrome population or not. Result show that the 20 metre multistage is not valid in order to measure the maximal oxygen consumption of the selected population.

Present study by Chatterjee, Banerjee [10] test the validity of 20 meter shuttle run for badminton player of India. The correlation between the criterion test, Bruce treadmill test and 20 meter shuttle run is 0.85 . Researcher concluded that this test is valid to test the selected population.

In the present study, the $2.4 \mathrm{~km}$ run test show low correlation with the criterion test $\quad(\mathrm{r}=.41, \mathrm{p}$ $=0.13 \mathrm{p}>0.05)$. This present research concluded that the $2.4 \mathrm{~km}$ test is not valid to test the maximal oxygen consumption of Malaysian healthy female adult. Past studied by O'Donnell, Smith [11] showed the correlation between the treadmill laboratory test and 2.4 test is high $(\mathrm{r}=$ 0.82). Compare to the present study, the selected population for this test were an army officer, the fitness level of the subjects is higher than the subject in present study, Malaysian healthy female adult. Researcher concluded that the $2.4 \mathrm{~km}$ test is valid to test aerobic fitness of army population. Other studies by [3] also test the validity of $2.4 \mathrm{~km}$ test for army population. In this study, the subjects also undergo treadmill laboratory test as criterion test. The correlation of treadmill test and $2.4 \mathrm{~km}$ test is 0.76 , which is the correlation a bit lower than past studies. This study also concluded that the $2.4 \mathrm{~km}$ test is valid to test aerobic fitness for army population. Fernhall and Tymeson [12], test validity of $2.4 \mathrm{~km}$ test for special population, which is mental retardate. Result of the studied show the negative correlation $(-0.88)$ exist between the $2.4 \mathrm{~km}$ test and criterion test, treadmill laboratory test. This studied concluded that the $2.4 \mathrm{~km}$ test is not valid to test the maximal oxygen consumption of mental retarded population.

The present study of one mile walk test show the correlation of one mile walk test with criterion test is low $(r=0.18, p=0.52, p>0.05)$. There is no significant correlation exist between the two tests. Past study by Kline, Porcari [13] showed the correlation exist between the criterion test, treadmill test and walk test were high $(\mathrm{r}=0.92)$. Compare to the present study, this study involved large sample, which is 343 subjects. So the reliability of the result is higher compared 
to present study that only involved fifth-teen female subjects. McSwegin, Plowman [14], found out that the one mile walk is acceptable to test the aerobic fitness of high school student aged between fourteen to eighteen years old. Treadmill walk test have been chosen as criterion test since the mode is the same as one mile walk test. The correlation coefficient for this study was 0.76. Then, other research by Beets and Pitetti [15] used different criterion test to test the validity of walk test. Researcher develop new field test named as PACER and correlate it with walk test. Result showed the correlation between PACER and one mile walk for male is 0.53 and for female is 0.63 . Researcher concluded that consistency of both test is low. Castro-Pinero, Mora [16] found out that the correlation between treadmill test and one mile walk test for female is higher than male which was 0.57 for male and 0.68 for female. 66 children aged eight to seventeen years old ware involved in this study.

This study showed that there is no significant correlation between the criterion test and Harvard Step test $(r=0.31, p=0.27, p>0.05)$. Past study by Pechar [17], the correlation exist between criterion test and step test is higher than the present study $(r=0.82)$. This study used 41 college women as subjects. Researcher concluded that step test valid to test aerobic fitness for selected population. Then, other studied by Sykes and Roberts [18], also found out that the correlation between treadmill test and step test is higher than present study $(r=0.92)$. Sixty-eight subject have been involved in this study, compared to the present study that involved fifth-teen subjects only. Researcher concluded that step test is valid field based test to test the aerobic fitness for population aged between eighteen to fifty-two years old.

As a conclusion, 20 meter multi-stage shuttle run test showed higher correlation compare to $2.4 \mathrm{~km}$ test, one mile walk, and Harvard Step test. It's proven that the most suitable cardiovascular test to measure $\mathrm{VO}_{2 \max }$ among healthy female adult is 20 meter multi-stage shuttle run test.

\section{REFERENCES}

[1] Castelli, D. and L. Williams, Health-related fitness and physical education teachers' content knowledge. Journal of Teaching in Physical Education, 2007. 26(1): p. 3-19.

[2] Lager, L. and J. Lambert, A maximal multistage 20-m shuttle run test to predict. Eur J Appl Physiol O, 1982. 49: p. 1-12. 
[3] Burger, S., S. Bertram, and R. Stewart, Assessment of the 2, $4 \mathrm{~km}$ run as a predictor of aerobic capacity. 1990.

[4] Oja, P. and B. Tuxworth, Eurofit for adults: Assessment of health-related fitness1995: Council of Europe.

[5] Brouha, L., Health, CW, \& Graybiel, A.(1943). Step Test Simple Method of Measuring Physical Fitness for Hard Muscular Work in Adult Men. Reviews of Canadian Biology. 2: p. 86.

[6] Noakes, T.D., K.H. Myburgh, and R. Schall, Peak treadmill running velocity during the V O2 max test predicts running performance. Journal of sports sciences, 1990. 8(1): p. 35-45.

[7] Barnett, A., L.Y.S. Chan, and I.C. Bruce, A Preliminary Study of the 20-m Multistage Shuttle Run as a Predictor of Peak $\mathrm{VO}<\mathrm{sub}>2</ \mathrm{sub}>$ in Hong Kong Chinese Students. Pediatric Exercise Science, 1993. 5(1): p. 42-50.

[8] Barnett, R.C., et al., Gender and the relationship between job experiences and psychological distress: a study of dual-earner couples. Journal of personality and social psychology, 1993. 64(5): p. 794.

[9] Guerra, M., K.H. Pitetti, and B. Fernhall, Cross Validation of the 20-Meter Shuttle Run Test For Adolescents With Down Syndrome. Adapted Physical Activity Quarterly, 2003. 20(1): p. 70.

[10]Chatterjee, P., et al., A Regression Equation for the Estimation of Maximum Oxygen Uptake in Nepalese Adult Females. Asian Journal of Sports Medicine, 2010. 1(1): p. 41-45. [11]O'Donnell, C., et al., Physical fitness of New Zealand army personnel; correlation between field tests and direct laboratory assessments--anaerobic threshold and maximum O2 uptake. The New Zealand medical journal, 1984. 97(760): p. 476-479.

[12]Fernhall, B. and G.T. Tymeson, Validation of cardiovascular fitness field tests for adults with mental retardation. Adapt. Phys. Activity Q. 5: 49, 1988. 59.

[13]Kline, G.M., et al., Estimation of VO2max from a one-mile track walk, gender, age, and body weight. Med Sci Sports Exerc, 1987. 19(3): p. 253-9.

[14]McSwegin, P.J., et al., The validity of a one-mile walk test for high school age individuals. Measurement in Physical Education \& Exercise Science, 1998. 2(1): p. 47-63. 
[15]Beets, M.W. and K.H. Pitetti, Criterion-referenced reliability and equivalency between the PACER and 1-mile run/walk for high school students. Journal of Physical Activity \& Health, 2006. 3: p. S21.

[16]Castro-Pinero, J., et al., Criterion-related validity of the one-mile run/walk test in children aged 8-17 years. Journal of Sports Sciences, 2009. 27(4): p. 405-413.

[17]Pechar, G.S.B., Shelley Reliability and interrelationships between maximal oxygen intake, physical work capacity and step-test scores in college women. Medicine and science in sports, 1972. 4(4): p. 182-186.

[18]Sykes, K. and A. Roberts, The Chester step test-a simple yet effective tool for the prediction of aerobic capacity. Physiotherapy, 2004. 90(4): p. 183-188.

\section{How to cite this article:}

S. H. Azmi and N. Sulaiman. Validity of Selected Cardiovascular Field-Based Test among Malaysian Healthy Female Adult. J. Fundam. Appl. Sci., 2017, 9(6S), 1127-1235. 